\title{
A Norma Hipotética Fundamental de Hans Kelsen e a Regra de Reconhecimento de Herbert Hart: semelhanças e diferenças entre os critérios de validade do Sistema Jurídico
}

\author{
The Hans Kelsen Fundamental Hypothetical Standard and the Herbert Hart \\ Recognition Rule: similarities and differences between the validity criteria of \\ the Legal System
}

\author{
Alex Silva Gonçalves \\ Faculdade Paraíso de Ceará, Juazeiro do Norte - CE, Brasil \\ Regio Hermilton Ribeiro Quirino \\ Faculdade Paraíso de Ceará, Juazeiro do Norte - CE, Brasil
}

Resumo: A validade do sistema jurídico foi pensada por jusfilósofos como Hans Kelsen e Herbert Hart, respectivamente, a norma hipotética fundamental e a regra de reconhecimento. Esse artigo enfrentará esses conceitos com o objetivo de realizar um estudo comparativo entre os dois e, então, apontar as suas semelhanças e diferenças. Para tanto, recorreu-se à abordagem dedutiva e à pesquisa de cunho bibliográfico. Ao final do artigo, será possível perceber a semelhança, construída a partir do positivismo jurídico, como um critério de validade para o ordenamento jurídico, e as diferenças pensadas a partir de pressuposto lógico-transcendental de validade (Kelsen) e do elemento de fato de validade (Hart).

Palavras-chave: Teoria do Direito. Norma Hipotética Fundamental. Regra de Reconhecimento.
Abstract: The validity of the legal system was thought by jus philosophers such as Hans Kelsen and Herbert Hart, respectively, the fundamental hypothetical norm and the rule of recognition. This article will address these concepts, with the goal of conducting a comparative study between the two, and then pointing out their similarities and differences. To do so, we used the deductive approach and bibliographic research. At the end of the article, similarities were perceived, both being theoretical constructions of legal positivism of criterion of validity for the legal order, and differences, a logical-transcendental presupposition of validity (Kelsen) as an element of fact of validity (Hart).

Keywords: Jurisprudence. Basic Norm. Recognition Rule.

Recebido em: 10/08/2017

Revisado em: 06/03/2018

Aprovado em: 05/04/2018 


\section{Introdução}

O pensamento jurídico do último século foi, para dizer o mínimo, efervescente. Vários autores ao redor do mundo puseram o Direito em constante crítica, desenvolvendo teorias e conceitos que buscavam um maior rigor na compreensão do fenômeno jurídico. Uma delas é a do pensamento jurídico positivista.

Uma das buscas fundamentais da ciência do Direito foi pelo fundamento de validade das normas jurídicas. A procura da questão fundamental da validade do Direito tem sido apresentada a partir de muitas teses, que foram, historicamente, do poder divino à fundamentação na natureza humana. Dois pensadores recentes contribuíram de modo significativo para essa busca: Hans Kelsen e Herbert Hart.

Kelsen buscou o fundamento de validade das normas jurídicas em uma norma hipotética fundamental, norma suprema que comanda a obediência do Direito baseado na sua própria pressuposição de obediência. Hart, por seu turno, sustenta que o fundamento de validade das regras é a regra de reconhecimento, atitude de reconhecer como Direito normas criadas sob determinada condição.

Diante disso, já seria possível indagar qual relação pode ser estabelecida entre esses dois critérios de validade, vez se prestarem, ambos, a tentar explicar a mesma coisa, o fundamento de validade do Direito dentro da mesma perspectiva teórica, o juspositivismo.

Esse artigo tem por objetivo geral estabelecer uma relação entre a norma hipotética fundamental de Hans Kelsen e a regra de reconhecimento de Herbert Hart. Para tanto, foram objetivos específicos, necessários à consecução desse fim, enfrentar os conceitos fundamentais dos critérios de validade de cada autor, trazendo, também, noções gerais a respeito das suas ideias, como condição pedagógica e esclarecedora que permita se chegar efetivamente ao objetivo geral.

Para tanto, empregou-se como método de abordagem, que indica a visão geral pela qual a pesquisa fora desenvolvida, o método dedutivo. A pesquisa se desenvolveu a partir da coleta de dados em fontes reputadas 
seguras, como livros e artigos científicos, consubstanciando a pesquisa bibliográfica.

A justificativa dessa pesquisa, trata-se de um trabalho de Teoria do Direito, destinado a aclarar conceitos do entendimento do próprio fenômeno jurídico enquanto tal. sobretudo, no debate acerca de conceito fundamental para o Direito, sua validade.

\subsection{Hans Kelsen e a Norma Hipotética Fundamental}

Uma das marcas indeléveis de Hans Kelsen é sua postura rigorosa em torno de uma "pureza" do Direito. Esta "pureza" passa necessariamente no pensamento kelsianiano pela construção lógico-jurídico de seus conceitos, por isso a necessidade do conhecimento, mesmo que de modo geral, do pensamento do jusfilósofo. Não confundindo a "pureza" com uma simples exclusão de conceitos ou critérios, mas ao contrário, a construção fundamental e fundamentada do critério de "pureza".

\subsubsection{Noções Gerais sobre o Pensamento de Kelsen}

O contexto histórico no qual se desenvolveu o pensamento kelseniano foi o da virada do século XIX para o século XX. Nessa época, percebeu-se a consolidação nos domínios científicos, das ciências naturais às ciências sociais. Certamente, um dos marcos filosóficos desse momento foi o pensamento positivista. Essa ideologia conseguiu abranger e determinar várias áreas do conhecimento, por exemplo, o campo jurídico, formatando assim o juspositivismo, que, mesmo não sendo um movimento homogêneo, possui uma base comum, a saber, a natureza da realidade positiva do Direito, ou seja, o Direito como ele é e não como deveria ser.

Inicialmente, é importante a observação feita no sentido de perceber a alteração da expressão positivismo para significar mais uma atitude epistemológica frente ao problema do conhecimento do que um movimento quase ideológico a respeito das ciências como um todo.

A sentença dada pelo autor citado acima é precisa, pois, realmente, a filosofia de Kelsen se constrói nesses paradigmas: a negação da possibilidade de existência de uma ordem jurídica além da imposta, pela vontade 
estatal, a partir de seus próprios parâmetros de validade e a aceitação da possibilidade de construção científica da ciência normativa. Dessa forma, considerando pensador juspositivista alguém alinhado a essas ideias, Kelsen é, sem dúvida, juspositivista.

O Círculo de Viena foi um conjunto de pensadores que se alinhava com Moritz Schlick na herança do pensamento de Wittgenstein, autor de Tractatus Logico-Philosophicus, inspiração máxima para o grupo. Em síntese, os seus membros advogavam pelo desenvolvimento de um positivismo lógico, raciocínio de inspiração positivista, mais temperado com a lógica moderna cujo mote era a distinção entre aquilo que é cognoscível pela ciência, portanto passível de atividade científica, e o que não o era, que fora relegado ao campo da metafísica.

A pretensão de Kelsen era precisamente a do grupo: dar autonomia científica ao que reputava ciência; no caso de Kelsen, especificamente, à ciência do Direito, estipulando seu âmbito de atuação/conhecimento enquanto tal, a partir de conceitos formados por ela mesma, ciência do Direito.

A influência do Círculo de Viena no pensamento do autor pode ser identificada em toda sua obra. As preocupações de Kelsen em $\mathrm{O}$ que é Justiça? são precisamente no sentido de buscar uma explicação científica para o conceito de justiça, para além da abordagem metafísica que o estudo de tal conceito invariavelmente termina por gerar (KELSEN, 1997).

Sobre o pensamento filosófico de Hans Kelsen, busca-se apenas o que foi delineado nos objetivos: estabelecer relação entre o conceito de norma hipotética fundamental de Kelsen e o de Regra de Reconhecimento de H. L. Hart.

\subsubsection{A Norma Hipotética Fundamental}

O pensamento de Kelsen foi desde a busca pelo fundamento último do direito à interpretação das normas jurídicas; do direito interno às relações de direito internacional; dos elementos objetivos do controle de constitucionalidade aos questionamentos sobre a justiça. 
A preocupação de Kelsen, como se disse, era com a possibilidade de estabelecer parâmetros científicos precisos para a ciência do direito. Certamente, para tanto, o jusfilósofo precisou enfrentar noções fundamentais presentes no pensamento jurídico, que são a pretensão de uma ordem normativa de identidade científica ou o fundamento de validade do Direito a partir de uma técnica universal.

A busca pela cientificidade do direito levou Kelsen a se preocupar com o fundamento da ordem jurídica. Tal fundamento, a bem da preservação do direito como ciência, não poderia se basear no poder divino ou na ordem da natureza. O próprio Kelsen (2009, p. 215) indaga:

Se o Direito é concebido como uma ordem normativa, como um sistema de normas que regulam a conduta de homens, surge a questão: O que é que fundamenta a unidade de uma pluralidade de normas, por que é que uma norma determinada pertence a uma determinada ordem? E esta questão está intimamente relacionada com esta outra: Por que é que uma norma vale, o que é que constitui o seu fundamento de validade?

Ao lado de outros problemas centrais - como o já referido problema da justiça ou como o problema da fiscalização da constitucionalidade das normas - o fundamento das normas jurídicas é problema nodal no pensamento de Kelsen.

Para ilustrar a busca do fundamento de validade das normas, Kelsen se vale da referência religioso. Para o jusfilósofo, as normas religiosas, como as expressas nos Dez Mandamentos do povo judeu ou no Mandamento do Amor de Jesus, devem ser obedecidas não por terem sido impostas por Jesus ou transmitidas por Deus ao povo de Israel, mas pela pressuposição de que devem ser obedecidas (KELSEN, 2009).

É interessante notar que, para Kelsen, o elemento de autoridade não é o mais importante, ainda no caso de se estar falando de uma norma emanada de um comando divino, que imagina ser superior, supra-humano.

Mesmo a autoridade conferida a alguém é consequência de uma norma mais fundamental, uma norma mais profunda, uma norma que se 
pressupõe como fundamental. Seguindo com o exemplo, obedece-se às normas dadas por Jeová ou por Jesus não devido ao seu aspecto autoritário como seres transcendentais, mas pela norma "[...] segundo a qual devemos obedecer às ordens ou mandamentos de Deus, ou aquela outra segundo a qual devemos obedecer aos mandamentos de Seu Filho" (KELSEN, 2009, p. 216).

De tal forma, para Kelsen, há uma norma que justifica, fundamenta a validade de todas as outras normas impostas. Trata-se da norma mais elevada, pois, para a teoria kelseniana, a norma que representa o fundamento de validade de outra é, em relação a esta, uma norma superior (KELSEN, 2009).

Ao se lançar à busca de uma norma fundamental, todavia, não se pode cair no problema lógico da busca pelo infinito, alerta o autor. Num contexto normativo plural, é possível que o cientista jurídico se perca no interminável. Ilustrando essa busca, pode-se exemplificar: há uma norma que impõe aos veículos o emplacamento com placas de determinadas especificações (tamanho, cor, conteúdo das placas). O fundamento de tal norma é outra norma, a que atribuiu àquela a competência de determinar as especificações do emplacamento de veículos. Essa, por sua vez, fundamenta-se noutra, e por aí vai.

Kelsen (2009, p. 217, grifo do autor) já alerta que essa busca pela norma fundamental:

[...] tem de terminar numa norma que se pressupõe como a última e a mais elevada. Como norma mais elevada, ela tem de ser pressuposta, visto que não pode ser posta por uma autoridade, cuja competência teria de se fundar numa norma ainda mais elevada. A sua validade já não pode ser derivada de uma norma mais elevada, o fundamento da sua validade já não pode ser posto em questão. Uma tal norma, pressuposta como a mais elevada, será aqui designada como norma fundamental (Grundnorm).

Então, pela leitura da passagem acima, extrai-se o conteúdo de norma fundamental, que seria a norma que baseia, sustenta, fundamenta - não há palavra melhor - as demais normas do ordenamento jurídico. 
Tal norma é uma norma pressuposta, pois se contrapõe às demais normas jurídicas, que são postas pelo poder estatal; mesmo a Constituição de um Estado é posta, ainda que seja a norma que cria o Estado. É importante que não se confunda a norma fundamental de kelseniana com a Constituição como norma positiva imposta pelo poder constituinte.

Desse modo, como descrito no exemplo do fundamento de obediência às normas religiosas, não se trata de obediência em razão da autoridade investida, mas sim a obediência baseada no pressuposto de obediência - pressuposto esse que consubstancia a norma hipotética fundamental. É a partir dessa visão que se encara a norma fundamental como uma "pressuposição lógico-transcendental”, em termos usados pelo próprio Kelsen.

Ao se valer desse termo, o autor em apreço se baseia em conceito da filosofia epistemológica de Kant. Confessa o próprio Kelsen (2009, p. 225):

Assim como Kant pergunta: como é possível uma interpretação, alheia a toda metafísica, dos fatos dados aos nossos sentidos nas leis naturais formuladas pela ciência da natureza, a Teoria Pura do Direito pergunta: como é possível uma interpretação, não reconduzível a autoridades metajurídicas, como Deus ou a natureza, do sentido subjetivo de certos fatos como um sistema de normas jurídicas objetivamente válidas descritíveis em proposições jurídicas?

O objetivo de Kelsen, como se percebe, é o de livrar o Direito dessas condições metafísicas de validade, em busca de algo que o lastreie de modo tangível, realmente normativo. Dessa forma, o Direito se caracteriza como uma autorreferência.

Mas a norma fundamental é o comando de obediência à Constituição, com ela não se confundindo. Da norma fundamental é, extraído, a máxima de que "devemos conduzir-nos como a Constituição prescreve".

Em outra passagem explica Kelsen (2009, p. 222, grifos nossos):

Nesse sentido, a norma fundamental é a instauração do fato fundamental da criação jurídica e pode, nestes termos, ser designada 
como constituição no sentido lógico-jurídico, para distingui-la da Constituição em sentido jurídico-positivo. Ela é o ponto de partida de um processo: do processo da criação do Direito positivo. Ela própria não é uma norma posta, posta pelo costume ou pelo ato de um órgão jurídico, não é uma norma positiva, mas uma norma pressuposta, na medida em que a instância constituinte é considerada como a mais elevada autoridade e por isso não pode ser havida como recebendo o poder constituinte através de outra norma, posta por uma autoridade superior.

Dessa forma, a Constituição em sentido jurídico-positivo é o que se pode identificar como norma fundamental de um Estado, aquela composta pelo texto normativo ou pelo conjunto de costumes de um país, ao passo que a norma fundamental é a máxima de obediência à norma constitucional imposta - positiva.

\section{Herbert Hart e a Regra de Reconhecimento}

Herbert Lionel Adolphus Hart (1907-1992) ao estabelecer um critério de validade do Direito, de prática do Direito, defende uma institucionalização, um padrão mínimo de aceitação daquilo que será válido juridicamente. A questão se coloca é, qual é este padrão? E como ele, padrão, se efetiva? A compreensão do pensamento de Hart proporcionará a elucidação destas questões.

\subsection{Síntese do Pensamento Jurídico de Hart}

Nesse momento passa-se a traçar somente linhas gerais a respeito do pensamento jurídico de Hart - tal como se fez com Kelsen - e apenas em um dos conceitos científicos do pensamento hartiano, o da regra do reconhecimento e a validade jurídica.

Hart era, sem dúvida, um pensador da Teoria do Direito. Tinha seus esforços filosóficos, suas ideias e sua produção acadêmica mais voltados (ainda que não exclusivamente) às questões gerais que abarcam o fenômeno jurídico. Nesse sentido, mais uma vez, Hart se inseria naqueles que 
buscavam analisar o Direito a partir de uma Teoria Geral (MACCORMICK, 2010).

Hart desenvolveu seus esforços teóricos sobre o Direito em O Conceito de Direito, de 1961. Obra capitular na filosofia hartniana, como diz MacCormick (2010, p. 35):

A teoria lá apresentada é de um sistema jurídico como um sistema de regras sociais, sociais em duplo sentido: elas tanto regem a conduta dos seres humanos em sociedades quanto devem sua origem e existência exclusivamente às práticas sociais humanas. Como regras sociais, pertencem a uma classe geral à qual também pertencem outros tipos diversos de regra, como regras de moral, de maneiras e etiqueta, de jogos, da fala etc. Dois aspectos as diferenciam dessa classe geral. O primeiro é que, tal como regras morais, elas se referem a "obrigações" ou "deveres", isto é, tornam certas condutas "obrigatórias" ou "vinculantes". Sendo assim, representam um tipo de razão "peremptória" para a ação. O segundo é que, diferentemente das regras morais, elas têm uma qualidade sistemática que depende da inter-relação de dois tipos de regras, as "regras primárias" e as "regras secundárias", como Hart as chamava.

A passagem mereceu ser colacionada, ainda que extensa, pela clareza sintética e explicativa a respeito do pensamento jurídico de Hart. Inicialmente, mostra como o pensador reconhece o Direito como regras de ordem social, seja por que nascem da sociedade, seja por que se prestam a regulamentar a vida humana no seio social. A seguir, o autor citado comenta um dos elementos centrais na teoria jurídica de Hart: a organização do Direito num sistema de regras primárias e regras secundárias.

É importante mencionar um elemento essencial na teoria de Hart, que é a da linguagem. Hart teve interesse pelas questões que envolvem a língua, a linguística e o uso da linguagem, tendo uma aproximação com a filosofia da linguagem.

Como comenta MacCormick (2010, p. 25): “[...] o Direito é, essencial e irredutivelmente, embora não exclusivamente, linguístico. [...] Assim sendo, o entendimento do Direito exige elucidação e análise da 
complexa estrutural conceitual envolvida". Em verdade, as formas de expressão do Direito são linguísticas. As normas jurídicas se expressam por meio de palavras repletas de significado. O comando normativo que se extrai de um enunciado não pode se desvincular dele.

Nesse sentido, a Teoria do Direito de Hart busca se alinhar a uma abordagem linguística do Direito. MacCormick (2010, p. 26) continua dizendo que "[...] um aspecto distintivo da obra de Hart é ser linguística em um sentido mais forte, pois ele foi um dos principais defensores do que costuma ser chamado de 'Análise Linguística' ou 'Filosofia da Linguagem Ordinária"”.

Os enunciados jurídicos a que o autor citado faz referência são as construções jurídicas, pertencentes ao mundo do Direito, que Hart identificou com o nome de regras. Para esse autor, tais regras, os comandos normativos - enunciados jurídicos - podem ser de duas naturezas, a saber, as regras primárias e as regras secundárias (HART, 2007). A identificação desses dois conceitos é um dos pontos culminantes da filosofia jurídica de Hart, tendo significado igualmente importante para um dos elementos do pensamento desse autor que será enfrentado, o da regra de reconhecimento.

Nada melhor do que trazer as palavras do próprio autor em estudo para delinear conceito tão fundamental, então. Diz Hart (2007, p. 91):

Por força das regras de um tipo, que bem pode ser considerado o tipo básico ou primário, aos seres humanos é exigido que façam ou se abstenham de fazer certas ações, quer queiram ou não. As regras do outro tipo são em certo sentido parasitas ou secundárias em relação às primeiras: porque asseguram que os seres humanos possam criar, ao fazer ou dizer certas coisas, novas regras do tipo primário, extinguir ou modificar as regras antigas ou determinar de diferentes modos a sua incidência ou fiscalizar a sua aplicação.

A passagem citada encerra o conceito de Hart a respeito da estrutura do próprio Direito, como conjunto de regras primárias e secundárias. Segundo o pensador, o direito é uma unidade de regras de duas naturezas: as primeiras são impositivas de condutas, omissivas ou comissivas. Servem 
para preencher o Direito de matéria, de conteúdo. São os comandos de fazer ou não fazer.

De outro lado, por regras secundárias se tem as regras procedimentais relativas às regras primárias. Para vencer problemas como, por exemplo, o caráter estático das regras primárias, que tenderiam a permanecer engessadas mesmo diante das mudanças sociais se não houvesse uma previsão de sua atualização, surgem regras secundárias, que disciplinam, nesse caso, a nova produção normativa (BARZOTTO, 2007). Outra forma de regras secundárias são as relativas à aplicação das regras primárias. Exemplo claro é o das normas processuais, que regulam a aplicação do tipo primário de regras.

Dessa forma, Hart identifica nesses dois tipos de regras a estrutura básica do ordenamento jurídico. Mas, afinal, onde repousa o fundamento de validade das regras que compõem o Direito, sejam elas de ordem primária ou secundária? Ao se questionar a respeito, Hart traz outro conceito, o de regra de reconhecimento.

\subsection{A Regra de Reconhecimento}

Para desenvolver seu pensamento, Hart partiu de uma teoria jurídica proposta por John Austin que encontrava certa adesão nos meios jurídicos ingleses na primeira metade do século passado. Como sintetiza Barzotto (2007, p. 99), Austin e os que adotam seu modelo “[...] não aceitam a noção de regra como elemento central do conceito de direito, preferindo reduzir o direito a um fenômeno isento de normatividade que pode ser descrito a partir de conceitos puramente factuais como 'ordens coercitivas' e 'hábitos de obediência"”.

Austin identifica que o elemento central do Direito é a obediência, motivada por um hábito social, às regras impostas pelo Poder Soberano. Esse pensamento, que tem sua origem nas teorias contratualistas - especialmente a de Hobbes - é criticado por Hart. Os primeiros capítulos de The Concept of Law são destinados justamente a tentar refutar o pensamento de Austin nesse particular, ainda que, de certa maneira, Hart continue aceitando outros elementos do pensamento de Austin (BARZOTTO, 2007). 
Para Hart (2007), o reconhecimento das leis passadas como direito não advém da adoção, por parte dos tribunais, funcionários ou mesmo do cidadão ordinário, de que o soberano atual tenha permitido, tacitamente, ao não revogar a legislação passada, que ela continuasse a gerar efeitos no presente. Na verdade, o que sustenta a aplicação, no momento atual, de leis impostas no passado é o recurso a um ou vários critérios sobre o que deverá ser considerado como Direito.

Como dito, Hart reconhece que há certa razão na teoria de Austin, pois, em que pese os problemas por ela gerados, realmente, o elemento coercitivo do Direito, identificado como a obediência às regras editadas pelo soberano, é algo que não pode ser ignorado ao se estudar o fenômeno jurídico. Por outro lado, Hart aponta que esse pensamento, por si só, é algo que reducionista, e precisa ser encarado por uma abordagem complementar. Afinal, reconhece-se como Direito uma regra apenas por que ela é emanada do Poder Soberano?

Comentando o relativo acerto da teoria de Austin e usando-a como ponto de partida para sua própria teoria acerca do conceito de Direito, Hart (2007, p. 111) diz:

Estas verdades [da teoria austiniana], porém, só podem ser claramente apresentadas, e a sua importância correctamente avaliada, nos termos de uma situação social mais complexa, em que uma regra secundária de reconhecimento seja aceite e utilizada para a identificação das regras primárias de obrigação. É esta situação que merece, admitindo que alguma o mereça, ser designada como fundamento de um sistema jurídico.

Já se falou sobre as regras primárias e secundárias, as quais se disse que aquelas são as normas que orientam as condutas humanas de maneira substantiva, apontando os fazeres e os não fazeres; estas, são normas procedimentais, de indicação do que fazer para se atingir as regras primárias, ou mesmo de como modificá-las segundo as normas de Direito ou, ainda, de como identificar as regras como Direito.

Hart acrescenta a essas regras secundárias a regra de reconhecimento. Trata-se essa regra um instrumento por meio do qual se pode reconhe- 
cer - daí seu nome - outras regras, primárias, como regras jurídicas. É o elemento de reconhecimento de uma norma, qualquer que seja sua natureza, como pertencente ao sistema jurídico em si, como válida.

A busca pela validade de uma imposição jurídica pode se dar pela procura das regras que a determinaram como impositiva, como existente. A título de exemplo, se se procura saber se um ato normativo de um Prefeito, regulando determinada matéria de determinado modo, é válido, pode-se buscar as regras que lhe atribuíram tal competência - a lei orgânica municipal, a Constituição Estadual ou mesmo a Constituição Federal, tomando por exemplo o ordenamento brasileiro.

Hart diz que, em determinado momento, chega-se a uma paragem em qualquer busca pelo fundamento de validade das regras. Partindo da realidade inglesa, esse momento se consubstancia quando se chega à máxima de que "[...] aquilo que a Rainha no Parlamento aprova é direito" (HART, 2007, p. 118). Partindo do exemplo acima, do ordenamento brasileiro, a busca iniciada no ato normativo do Prefeito atingiria, por último, a Constituição, atingindo, então, a máxima de que "aquilo que está em acordo com a Constituição é Direito".

Esse axioma consiste na regra de reconhecimento. É ela uma noção geral, um entendimento implícito de que algo que está em acordo com determinado quadro normativo é válido, deve ser obedecido. Como diz Hart (2007, p. 113), “[...] na maior parte dos casos a regra de reconhecimento não é enunciada, mas a sua existência manifesta-se no modo como as regras concretas são identificadas, tanto pelos tribunais ou outros funcionários, como pelos particulares ou seus consultores".

Hart segue analisando a regra de reconhecimento, destacando que essa regra - e todas as outras, na verdade - podem ser vistas a partir de um ponto de vista interno ou de um ponto de vista externo (HART, 2007). Quando um enunciado aponta que a manifestação daquele que observa o direito é no sentido de sua aceitação, de seu reconhecimento, há a manifestação da regra de reconhecimento e, portanto, aquela pessoa aceita a norma como válida. É o ponto de vista interno. No outro sentido, quando um observador afirma que consegue identificar que determinado fenôme- 
no em determinada ordem é válido juridicamente - é jurídico, é Direito, tem-se o ponto de vista externo.

Ao postular a regra de reconhecimento, o próprio Hart (2007, p. 123) alerta que:

Devemos recordar que a regra última de reconhecimento pode ser vista de duas perspectivas: uma está expressa na afirmação externa de facto de que a regra existe na prática efetiva do sistema; a outra está expressa nas afirmações internas de validade, feitas por aqueles que a usam para identificar o direito.

A saída de Hart para um problema crucial do positivismo jurídico, que é onde os fatos sociais se entrelaçam e como se relacionam com o fenômeno jurídico - que deve ser independente -, foi identificar na regra de reconhecimento um caráter fático, a partir do observador externo, que identifica uma prática social de se reconhecer como Direito determinadas regras e um caráter normativo-validador, a partir do ponto de vista interno, daquele que usa da regra de reconhecimento para perquirir a validade de determinada regra.

Por último, é importante destacar a posição da regra de reconhecimento para o ordenamento jurídico no pensamento de Hart. O que se pode intuir, a partir do que foi dito, é que a regra de reconhecimento é, no pensamento desse autor, o fundamento de validade do conjunto de regras primárias e secundárias a que se pode chamar de um sistema jurídico.

Nada melhor para ilustrar essa afirmação do que a citação do próprio autor, pois segundo Hart (2007, p. 117):

A regra de reconhecimento, que faculta os critérios através dos quais a validade das outras regras dos sistemas é avaliada, é, num sentido importante que tentaremos clarificar, uma regra última: e onde, como é usual, há vários critérios ordenados segundo a subordinação e a primazia relativa, um deles é supremo.

A ideia de que a regra de reconhecimento é uma regra última está relacionada ao seu posicionamento como último fundamento de validade 
de determinado ato. Como já exemplificado, se se quer saber a validade de um ato normativo de um Prefeito Municipal é possível fazer uma digressão de regras até a regra de reconhecimento de que "o que está de acordo com a Constituição é Direito". Assim, por essa máxima ser a responsável pelo encerramento dessa digressão, e por ser ela a regra de reconhecimento, diz-se que é a regra última.

\section{Semelhanças e Diferenças entre os Critérios de Validade do Sistema Jurídico de Kelsen e Hart}

Ao chegar ao fim das apresentações dos autores envolvidos e suas teorias, mesmo que minimamente, se faz necessário fazer uma análise comparativa, no sentido de explicar, caso haja, as semelhanças e diferenças entre ambos.

\subsection{Semelhanças entre os Critérios de Validade do Ordenamento Jurí- dico de Kelsen e de Hart}

Inicialmente, a primeira semelhança que se pode traçar é algo contextual, de identificação de um método de pensamento entre os dois autores. A atividade investigativa como um todo de Kelsen e Hart - e, assim, os seus conceitos jurídicos, como o de validade - é orientanda ao movimento de pensamento que se convencionou chamar de positivismo jurídico.

O próprio Hart (2007) se identifica como positivista literalmente, no Pós-escrito de sua obra O Conceito de Direito, quando estabelece diálogo extremamente interessante com as críticas que lhe foram feitas por Ronald Dworkin. A postura positivista de Kelsen pode ser extraída já nas primeiras páginas da sua Teoria Pura do Direito, no qual o autor determina o tipo de ciência que estava a fazer - a ciência jurídica positiva (KELSEN, 2009).

De tal sorte, essa identificação de ambos os autores como positivistas, dá azo a identificar outra semelhança, essa mais importante neste mo- 
mento, entre o pensamento desses autores: ambos buscavam um critério de validade para o Direito.

Para completar essa busca, Kelsen elaborou o critério da norma hipotética fundamental. Como dito, segundo esse jurista, as normas positivas, sejam elas os textos legislativos ordinários ou a norma constitucional fundamental; sejam elas os costumes, sejam elas a sedimentação dos precedentes judiciais, todas encontram fundamento de validade numa norma pressuposta de que tais normas devem ser obedecidas.

A norma hipotética fundamental baseia o ordenamento jurídico e suas normas por meio da máxima de que "devemos obedecer à Constituição" ou "devemos obedecer aos precedentes judiciais" ou ainda "devemos obedecer aos costumes". É hipotética porque se situa como fundamento de validade pressuposto para a norma mais importante do ordenamento jurídico - a Constituição, nos países que a adotam - ou o paradigma mais importante para o ordenamento - o da soberania do Parlamento, em sistemas como o da Inglaterra.

É interessante perceber, ainda, que se trata de um elemento teórico pensado à luz do pensamento kantiano, posto tratar a norma fundamental como um conceito transcendental, situando-o para além da construção escalonada entre as normas jurídicas que tornou Kelsen conhecido - sua famosa "pirâmide normativa".

Já Hart, no intento de satisfazer a questão do fundamento de validade, identificou-o como sendo a regra de reconhecimento. Foi trazido, linhas acima, que Hart considera que as regras primárias e secundárias de um ordenamento - os comandos de fazer ou não fazer e as regras de organização do sistema jurídico, garantidoras da aplicação das regras primárias ou as viabilizadoras de sua alteração -, para serem consideradas válidas, precisam ser reconhecidas como tal.

Tal reconhecimento pode se dar por meio da busca formal da regra que fundamenta a regra que se quer saber da validade. Todavia, chega um momento em que esse movimento investigativo esbarra numa máxima, a de que "essa regra é válida porque emanou da Rainha decidindo no Parlamento", dentro dos exemplos de Hart, ou de que "essa regra é válida por- 
que está em conformidade com a Constituição", trazendo sua teoria para uma abordagem de estado constitucional. Desse modo, a regra de reconhecimento é o entendimento de que tal regra é válida porque se adequa a uma dada situação reconhecida como responsável por conferir validade às regras jurídicas.

Dito isso, quais as semelhanças propriamente ditas entre o critério de validade de Hans Kelsen e Herbert Hart?

Primeiramente, ambos os critérios têm a pretensão de resolver o problema da validade do ordenamento jurídico cientificamente, e não a partir de qualquer ciência, mas da ciência do Direito (pura, para Kelsen). Sobre isso já se disse. Entretanto, ainda que tenham essa pretensão, é uma semelhança entre esses critérios o não afastamento total do aspecto factual em sua construção.

Tanto a norma hipotética fundamental quanto a regra de reconhecimento, apesar de se construírem com a pretensão científica da autonomia do Direito, não conseguem afastar um quê de fato - um fato social - da validade normativa. $\mathrm{Na}$ verdade, é talvez nesse ponto que tanto a teoria kelseniana quanto o modelo de Hart ficam mais flanqueados, mais sujeitos à interferência social.

Kelsen (2005) é muito reticente em admitir que a norma fundamental possua alguma identificação com elementos fáticos. Segundo Kelsen (2009, p. 222), “[...] a norma fundamental é a instauração do fato fundamental da criação jurídica e pode, nestes termos, ser designada como constituição no sentido lógico-jurídico".

A noção que se tem aí é que a norma hipotética fundamental é, em algum momento, um fato, um fato pressuposto. Pressupõe-se que dado fato criativo - como, por exemplo, a promulgação de um texto constitucional em um determinado momento histórico - irá sustentar a máxima de validade que é a norma hipotética fundamental. Pressupõe-se que a culminância daquele fato é o que encerra a validade de uma norma.

Hart, por sua vez, é mais aberto à noção de que a regra de reconhecimento se baseia em práticas factuais. Como dito, esse autor afirma que seu critério de validade pode ser observado de modo interno, em que 
representa a identificação do Direito e se expressa apenas como caráter de validade. Mas, também, pode ser observado como um fato, a partir de um ponto de vista externo, por parte daqueles que não aceitam a regra que se pretende perquirir a validade.

Como diz Barzotto (2007, p. 133),

A regra de reconhecimento de Hart é um pressuposto social (é uma norma que expressa uma efetiva prática de funcionários na identificação de normas), e, como tal, depende diretamente da situação fática. É uma regra formulada por aqueles que assumem determinados modos de produção do direito como "legítimos".

Então, ainda que se busque, com o critério de validade desses pensadores do Direito, livrá-lo das forças metafísicas ou de identificação de um Direito Natural como fundamento de sua validade, não se pode livrá-lo, mesmo nesse critério, das influências sociais que, para Hart, são fundamentalmente ligadas ao reconhecimento das normas como Direito, a partir da ação prática e, para Kelsen, baseiam a máxima da norma fundamental.

Outra semelhança que se pode perceber entre os critérios de validade estudados é a relativa ao conteúdo do Direito. Nem Hart nem Kelsen baseiam a validade de suas normas naquilo que é considerado bom ou justo. Kelsen (2009, p. 244) é enfático em dizer que:

[...] a Teoria Pura do Direito, enquanto teoria jurídica-positivista, não fornece, com a norma fundamental do Direito positivo por ela definida, qualquer critério para apreciação da justiça ou injustiça daquele Direito e, por isso, também não fornece qualquer justificação ético-política do mesmo [...].

A Teoria Pura não se preocupa das questões éticas ou políticas, ditas valorativas, em sentido amplo, relativas às normas jurídicas. Sua preocupação é com a validade da norma, a partir de um critério, que é, para Kelsen, o da norma hipotética fundamental - "deve-se obedecer à Constituição; às normas costumeiras; aos precedentes judiciais". 
Apesar do contexto diferenciado do direito britânico, argumento do pensamento jurídico de Hart, no qual a relação entre o direito e a política é de difícil cisão, o que poderia implicar um Direito permeado de elementos estranhos, esse autor também não parece se dedicar, ao falar da regra de reconhecimento, à questão dos valores que podem preencher o conteúdo das regras fundamentadas na regra de reconhecimento, sejam elas primárias ou secundárias. Hart não trouxe como requisito da regra de reconhecimento que as regras "sejam justas", "representem a verdade" ou outras colocações. Serão válidas por respeitarem a regra de reconhecimento, e é tudo.

Então, em síntese, as semelhanças entre a norma hipotética fundamental de Kelsen e a regra de reconhecimento de Hart são: ambas são construções teóricas do positivismo jurídico; as duas podem ser chamadas de critério de validade para o ordenamento jurídico, pois buscam responder à questão da validade; tanto um quanto o outro critério buscam a desvinculação do Direito a elementos valorativos como justiça e verdade; ambos os critérios, apesar dessa busca, acabam se rendendo, em algum momento, a aspectos factuais da sociedade.

\subsection{Diferenças entre os Critérios de Validade do Ordenamento Jurídico de Kelsen e de Hart}

Uma vez enfrentadas as semelhanças entre os critérios de validade do ordenamento jurídico em Kelsen e em Hart, cabe agora analisar os pontos que podem ser indicados como de diferenças entre essas duas teorias.

Inicialmente, há que se notar uma diferença de ordem contextual, que acabará importando em outras diferenças mais específicas, entre os dois autores. Kelsen é herdeiro da tradição jurídica da Europa continental, baseada na codificação, no Império da Lei, nas construções normativas feitas abstratamente. Hart está situado num sistema jurídico baseado nos costumes, na força normativa dos precedentes, na produção do Direito posterior aos fatos e intimamente relacionada a eles.

Acaba sendo muito importante a diferença de realidades jurídicas nos quais cada autor estava inserido. Na tradição romano-germânica, cognominada civil law, contexto de Kelsen, a produção normativa é baseada 
em tipos normativos abstratos veiculados pelos poderes estatais (especialmente, o poder competente para criar as leis como atos mais abstratos). Para a tradição na qual está inserto Herbert Hart, a chamada common law, a produção normativa tem por base a fixação de standards por meio das decisões judiciais posteriores a fatos submetidos aos órgãos judicantes (LOSANO, 2007).

Compreender essa diferença permite entender, por exemplo, o motivo pelo qual a regra de reconhecimento de Hart é muito mais voltada a uma questão social - o reconhecimento da autoridade do soberano - do que a ideia da norma fundamental pensada por Kelsen.

Apesar de a teoria de Kelsen ter influenciado o pensamento de Hart, o contexto jurídico dos dois autores era diferente. O modo de produção, de valoração e de reconhecimento do fenômeno do Direito, bem como seu arcabouço prático e teórico eram diferentes. Hart teve que trilhar um caminho diferente, bebendo em fontes teóricas diferentes. Segundo MacCormick (2010, p. 42-43):

Hart reconheceu diversas vezes a sua dívida para com a análise da ordem jurídica de Kelsen [...]. Suas próprias preocupações hermenêuticas, porém, levaram-no a desenvolver uma concepção de regras, deveres e autoridade que relaciona esses conceitos tanto com contextos sociais específicos quanto com atitudes individuais ou de grupo. Ao fazê-lo, ele rejeitou o programa de Kelsen de uma teoria "pura" do Direito; sua própria dívida aqui é, em última análise, com Hume, enquanto a de Kelsen é com Kant.

Os pensamentos de Kelsen e Hart, apesar de alinhados ao positivismo e às mesmas preocupações epistemológicas e científicas, desenvolvem-se em um solo diferente: para Hart, a experiência, as práticas sociais, os fatos, têm relevância para a teoria do Direito; para Kelsen, o apriorismo normativo é a tônica principal.

Essa diferença contextual implica uma diferença específica entre os conceitos de norma hipotética fundamental e regra de reconhecimento que já foi abordada quando se tratou das semelhanças entre ambas. Foi dito que ambas, apesar de se preocuparem com a validade jurídico-posi- 
tiva, acabavam cedendo espaço, ao final, às influências sociais, seja no momento último da análise da norma fundamental, seja no reconhecimento das regras por meio das práticas de órgãos, funcionários e do próprio cidadão.

Mas nisso já há uma diferença: Hart admite com muito mais abertura a ingerência dos dados sociais no aspecto validador das normas jurídicas, admissão essa que se encontra em Kelsen de maneira muito sutil. Barzotto (2007, p. 132-133) já escreve nesse sentido:

A norma fundamental de Kelsen é um pressuposto lógico (é uma norma "pensada") de uma constituição eficaz. Com a mudança da constituição, muda-se a norma fundamental. Ela encontra-se, desse modo, em estreita dependência dos fatos. [...] A regra de reconhecimento de Hart é um pressuposto social (é uma norma que expressa uma efetiva prática de funcionários na identificação de normas) e, como tal, depende diretamente de uma situação fática.

Assim sendo, a norma hipotética fundamental de Kelsen é um critério de validade lógico, apriorístico, transcendental. A regra de reconhecimento de Hart é um critério fático. Dito isso, e a partir dessa colocação, que por si só já encerra uma diferença significativa entre esses critérios de validade, é possível apontar outra diferenciação entre a norma fundamental e a regra de reconhecimento, que é o elemento da pressuposição.

Para Kelsen, a norma hipotética fundamental é pressuposta, pois, ao contrário das outras normas, que são postas pelo ente de produção do Direito, a Grundnorm se baseia na pressuposição de que é ela a mais elevada das normas, por ser o fundamento de validade das demais. Dessa forma, trata-se de uma pressuposição ficta, admitida literalmente pelo próprio Kelsen como fundamento lógico-transcendental.

Hart também identifica um elemento de pressuposição na regra de reconhecimento, mas sua noção de pressuposição é diferente da de Kelsen. Enquanto a norma fundamental é pressuposta por si só, a pressuposição na regra de reconhecimento é identificada como uma aceitação tácita de sua existência. 
Segundo Barzotto (2007, p. 121): “[...] a regra de reconhecimento é uma regra pressuposta por aqueles que a utilizam, na medida em que raramente é enunciada. Ao contrário de Kelsen, onde pressuposto opõe-se a posto, aqui pressuposto se opõe a explicitado”. Quer-se dizer com isso que a regra de reconhecimento possui um caráter de aceitação, de reconhecimento implícito na prática social. Ao se reconhecer algo como Direito por meio de uma máxima de regra de reconhecimento faz-se isso de modo não expresso, não explicitado.

Outra passagem de Barzotto (2007, p. 105) esclarece bem a pressuposição: "Para Hart, a regra de reconhecimento não é pressuposta, mas envolve dois pressupostos: a aceitação por parte daquele que faz um juízo de validade da regra; em segundo, a aceitação de tal regra por parte dos funcionários do sistema".

Desse modo, a pressuposição da norma fundamental é diferente da pressuposição na regra de reconhecimento. Aquela tem o aspecto de pressuposição ligado a sua própria identificação como norma mais elevada do ordenamento jurídico; para esta, a pressuposição tem a ver com a aceitação não explicitada, tácita, das regras enquanto válidas porque a observam como critério de validade.

Mais uma diferença pode ser percebida entre a norma fundamental de Kelsen e a regra de reconhecimento de Hart: ambas estão preocupadas com o elemento da eficácia do Direito de maneira diferente.

A eficácia é o efeito natural das normas no seio social; sua aceitação, sua prática no cotidiano (KELSEN, 2009). A eficácia, para a teoria kelseniana, liga-se de maneira muito importante à noção de validade e, portanto, de norma hipotética fundamental. Kelsen enxerga - e dá relevo a isso - a eficácia como uma condição da validade, mas que não deve ser confundida com ela (KELSEN, 2009). A norma fundamental é pressuposta ao se falar em eficácia, de maneira geral.

Segundo Kelsen (2009, p. 236):

[...] a eficácia da ordem jurídica como um todo e a eficácia de uma norma jurídica singular são - tal como o ato que estabelece a norma - condição da validade. Tal eficácia é condição no sentido de que 
uma ordem jurídica como um todo e uma norma jurídica singular já não são consideradas como válidas quando cessam de ser eficazes.

Hart vai mais para o sentido contrário. Para ele, a única maneira de reconhecer a eficácia como pertencente à regra de reconhecimento é se o próprio elemento da eficácia estiver contido na regra de reconhecimento. Aponta Hart (2007, p. 115) que:

Se por eficácia se quer dizer que o facto de que uma regra de direito exigindo certo comportamento é mais frequentemente obedecida do que desobedecida, é evidente que não há relação necessária entre a validade de uma regra concreta e a sua eficácia, a menos que a regra de reconhecimento do sistema inclua entre os seus critérios, como o fazem algumas, a disposição (por vezes referida como regra de desuso) de que nenhuma regra é considerada como regra do sistema se tiver cessado há muito de ser eficaz.

Então, não há relação intrínseca entre a regra de reconhecimento e o elemento da eficácia. A não ser que faça parte da própria máxima que consubstancia a regra de reconhecimento o elemento da eficácia, para Hart não é condição de validade a própria eficácia, independentemente considerada.

Dito isso, pode-se apontar como elementos distintivos entre a norma hipotética fundamental e a regra de reconhecimento: o contexto jurídico no qual cada conceito fora desenvolvido, sendo aquela gestada no seio do Direito de tradição legalista e está no âmbito do Direito consuetudinário baseado nos precedentes judicias; ser a norma fundamental um pressuposto lógico-transcendental de validade e a regra de reconhecimento um elemento de fato de validade; ser a norma fundamental uma pressuposição fundamental e a regra de reconhecimento ser baseada numa aceitação pressuposta; o elemento da eficácia ter relação indissociável do conceito de norma hipotética fundamental, apesar de não se confundir com ele e, para a regra de reconhecimento, a eficácia ter função meramente acessória, que precisa de reconhecimento por ela mesma para gozar de importância. 


\section{Conclusão}

Uma das primeiras considerações finais que podem ser traçadas é a de que, sendo a teoria jurídica matéria tão complexa, não se pretendeu com esse singelo artigo esgotar o tema ou muito menos fechar as questões que envolvem a temática abordada. $\mathrm{Na}$ verdade, quis-se apenas contribuir, de maneira modesta, com as pulsantes questões envolvendo dois autores que, apesar de não estarem mais vivos, continuam exercendo influência sobre o mundo jurídico nos dias de hoje. Parta-se então às considerações finais acerca desse trabalho.

Em um primeiro momento, Kelsen e seu pensamento foram estudados, dando relevo a sua posição dentro do movimento filosófico do positivismo. Temas gerais como a busca pela objetividade da ciência do Direito, pela sua autonomia e, por fim, o tema específico da filosofia de Kelsen voltada para a identificação da norma fundamental foram tratados. Sobre isso, foi dito que a norma hipotética fundamental de Kelsen consiste no fundamento de validade do ordenamento jurídico, identificado como a ordem mais elevada de obediência, à Constituição, aos precedentes ou aos costumes, o que irá orientar a validade de todas as outras normas.

Partindo dos conceitos jurídicos mais básicos de sua teoria do direito, foi demonstrado que, em Hart, o fundamento de validade do sistema jurídico é percebido por uma máxima de identificação - de reconhecimento - de algo como Direito porque é decidido pela Rainha no Parlamento, em seus exemplos, ou porque está em acordo com a Constituição e, o que assim está, é Direito.

As semelhanças entre a norma hipotética fundamental de Kelsen e a regra de reconhecimento de Hart são: ambas são construções teóricas do positivismo jurídico; as duas podem ser chamadas de critério de validade para o ordenamento jurídico, pois buscam responder à questão da validade; tanto um quanto o outro critério buscam a desvinculação do Direito a elementos valorativos como justiça e verdade; ambos os critérios, apesar dessa busca, acabam se rendendo, em algum momento, a aspectos factuais da sociedade. 
As distinções entre norma hipotética fundamental de Kelsen e a regra de reconhecimento de Hart são: o contexto jurídico no qual cada conceito fora desenvolvido, sendo aquela gestada no seio do Direito de tradição legalista e está no âmbito do Direito consuetudinário baseado nos precedentes judicias; ser a norma fundamental um pressuposto lógico-transcendental de validade e a regra de reconhecimento um elemento de fato de validade; ser a norma fundamental uma pressuposição fundamental e a regra de reconhecimento ser baseada numa aceitação pressuposta;

Como é possível perceber, as semelhanças e diferenças são significativas. Dizer se os critérios de validade dos autores possuem mais semelhanças do que diferenças poderia implicar uma abordagem limitadora. A melhor compreensão das duas construções é a partir da análise aprofundada e comparativa de cada uma delas.

\section{Referências}

ARGÜELES, Juan Ramon de Pavamo. H. L. A. Hart e a Teoria Analítica do Direito: Prólogo de Gregório Peres Borba. Madrid: Centro de Estudos Constitucionais, 1984.

BARZOTTO, Luis Fernando. O positivismo jurídico contemporâneo: uma introdução a Kelsen, Ross e Hart. São Leopoldo: UNISINOS, 1999. COELHO, Fabio Ulhoa; FERRAZ JR., Tércio Sampaio. Para entender Kelsen. São Paulo: Saraiva, 2007.

FERRAZ JÚNIOR, Tércio Sampaio. Hans Kelsen, um divisor de águas 1881-1981. Sequência: Estudos Jurídicos e Políticos, Florianópolis, v. 3, n. 4, p. 133-138, jan. 1982. Disponível em: <https://periodicos.ufsc.br/ index.php/sequencia/article/view/17161>. Acesso em: 16 ago. 2015.

HART, Herbert L. A. O Conceito de Direito. Trad. de Armindo Ribeiro Mendes. 3. ed. Lisboa: Calouste Gulbenkian, 2007.

KELSEN, Hans. O que é Justiça? A Justiça, o Direito e a Política no espelho da ciência. Trad. de Luís Carlos Borges. São Paulo: Martins Fontes, 1997. 
. Teoria Pura do Direito. Trad. de João Baptista Machado. 8. ed. São Paulo: Martins Fontes, 2011.

LADAVAC, Nicoletta Bersier. Hans Kelsen (1881-1973): biographical note and bibliography. European Journal of International Law 9. (1998). p. 391-400.

MACCORMICK, Neil. H. L. A Hart. Trad. Cláudia Santana Martins. Rio de Janeiro: Elsevier, 2010.

MICHELON JR., Cláudio Fortunatto. Aceitação e objetividade: uma comparação entre as teses de Hart e do positivismo precedente sobre a linguagem e o conhecimento do direito. São Paulo: Revista dos Tribunais, 2004.

\begin{abstract}
Alex Silva Gonçalves é mestre em Direito na área de concentração Direito Sociais e Políticas Públicas na linha de pesquisa de Políticas Públicas de Inclusão Social pela Universidade de Santa Cruz do Sul (UNISC). Graduado em Direito pela Universidade Regional do Cariri (2006). Advogado Militante com Pós-graduação em Direito Ambiental em Direito Penal Militar e Processual Penal Militar pela Faculdade Unileya. Professor na Faculdade Paraíso (FAP). Professor dos Cursos de Pós-graduação Lato Sensu da Faculdade Paraíso do Ceará (FAP).

E-mail: dralexgoncalves@hotmail.com.
\end{abstract}

Endereço profissional: Rua da Conceição, 1.228, São Miguel, Juazeiro do Norte. CEP: 63010-220.

Regio Hermilton Ribeiro Quirino é doutorando em Filosofia pela Universidade Federal do Ceará (2017). Graduado em Filosofia pela Universidade Estadual do Ceará (1999) Mestrado em Filosofia pela Universidade Federal do Ceará (2003). Formação na área de tutoria a distância pela UFC, programa de Tutoria em células de Educação Continuada para Humanidades (2007), Formação de Tutores em Educação a Distância pela UFC (2009). Especialista em Docência do Ensino Superior pela Faculdade Católica do Cariri (2014). Atualmente é Coordenador de 
Extensão e Pós-graduação da Faculdade Paraíso do Ceará e professor do Curso de Direito e Psicologia da Faculdade Paraíso do Ceará.

E-mail: regio.quirino@fapce.edu.br.

Endereço profissional: Rua da Conceição, 1.228, São Miguel, Juazeiro do Norte. CEP: 63010-220. 
